\title{
Contrabando, ilegalidade e medidas políticas no Rio de J aneiro do século XVIII
}

Ernst Pijning M inot State University, North Dakota, U.S.A. ${ }^{1}$ Tradução de Cristina M en eguello.

\section{RESUM O}

0 presente artigo estuda o contrabando no século XVIII, em especial em relação ao Rio de Janeiro eao Atlântico Sul. Neste artigo discuto não apenas a mecânica do contrabando e os participantes deste comércio ilegal, masos vários fatores que ocasionaram as medidas portuguesas, metropolitanas e coloniais para impedir o comércio clandestino. Estudo particularmente como tais medidas representaram um compromisso entre diferentes interesses, tais como: o papel do monar$c a$, a integridade ou a mal eabilidade da autoridade real, a aplicação dessa legislação e os tipos de penalidades impostas aos infratores, trazendo questões sobre o que constituíam ações legais ou ilegais, assim como questões mais amplas relativas à ética e à moralidade pública no Brasil colônia.

Palavras-chave: contrabando; mentalidades; mercantilismo.
ABSTRACT

This article focuses on contraband in the eighteenth century, with special referenceto Rio deJ aneiro and theSouth Atlantic. It discusses not merely the mechanics of contraband and the participants in this illegal trade, but the many factors that contributed to Portuguese metropolitan and colonial measures to curb clandestine trade. I am particularly intrigued by the degreeto which such measures represented a compromise between different interests. The role of the monarch, theintegrity or malleability of royal authority, thelatitudein enforcement of such legislation and the range of penalties imposed on infractors raisequestions as to what constituted legal or illegal actions, as well as broader issues of ethics and public morality in colonial Brazil.

Keywords: contraband trade; mentalities; mercantilism. 
H istórias sobre contrabandistas capturam de forma vívida a imaginação. Evocam imagens de heróis como Robin Hood, de assassinos como El Capone ou de degradados como os piratas, cuja existência é sintoma de uma economia ou administração pouco desenvolvidas. Este artigo devolve os contrabandistas a seu lugar de direito no mundo lusófono do século XVIII, ou seja, como empreendedores que pertenciam ao sistema, com boas conexões com as elites governantes. Desse modo, analisar o contrabando torna-se um instrumento chave para estudar a sociedade colonial brasileira. Não apenas o estudo do contrabando fornece uma possibilidade para se entender o funcionamento do mercantilismo, do sistema jurídico e da ética pública e privada no mundo luso-brasileiro, como também possui implicações amplas para nossa compreensão dos valores e do comportamento coletivo no Atlântico colonial.

Dentre todas as colônias portuguesas, o controle metropolitano era mais forte no Rio de Janeiro, cujo porto servia como um centro político, administrativo e militar para o Atlântico Sul. H avia uma constante troca de ouro, diamantes e outros produtos entre o Rio de Janeiro e os distritos mineiros. Um dos poucos portos de mar aberto, o Rio atraía muitos estrangei ros navegando para os M ares do Sul ou para o oceano Índico, era a porta de entrada para o tráfico de escravos com a África e para a cabotagem com o rio da Prata. 0 Rio de Janeiro permanecia em contato constante e direto com Lisboa, possibilitado pelas infalíveis frotas anuais. Quando se tornou sede do vice-reinado em 1763, o Rio já era um grande centro administrativo da região sul e da re gião das minas sob Gomes Freire de Andrade (1733-1762).

Talvez devido a seu caráter ilusivo, o contrabando, de modo geral, não foi profundamente estudado. Além disso, o tema sofreu preconceitos de ordem moral e econômica. Allan Christolow, um historiador britânico da primeira metade do século XX, é um exemplo nítido desse tipo de historiografia. Ele produziu uma história político-econômica do comércio ilegal das colônias portuguesas e espanholas, admitindo que o comércio ilegal era uma das dimensões do mercantilismo. ${ }^{2}$ Christolow afirmou que a Grã-Bretanha possuía uma economia superior à de Portugal e que, portanto, o Estado português não tinha os meios para impedir que os ingleses fizessem contrabando. Para essas afirmações, o historiador apoiava-se nas elites diplomáticas e políticas do século XVIII, que legitimaram e estimularam o contrabando com os mesmos argumentos. Porém, o contrabando estava presente em toda a Europa e nas colônias européias, mesmo na Grã-Bretanha e nas colônias britânicas na América.

N as décadas de 1960 e 1970, argumentos como os de Christolow foram adotados e reconceitualizados por historiadores partidários da teoria da dependência, como Sandro Sideri e especialmente Fernando Novais. Portugal 
era visto como econômica, militar e politicamente subordinado à I nglaterra, situação formalizada pelo Tratado de M ethuens. Assim, segundo essa versão, o rei português explorava o Brasil mas não conseguia lucrar com isso, já que Portugal era roubado pela Grã-Bretanha. 0 contrabando, de acordo com Fernando N ovais, não estava em contradição com o sistema de exploração, sendo sintoma e parte integral do mundo colonial lusófono. A própria existência do comércio ilegal demonstrava ao mesmo tempo a força, a fraqueza e a flexibilidade inerentes ao sistema colonial.

A partir da década de 1980 os historiadores afastaram-se desse conceito rígido de exploração da periferia pelo centro, buscando uma análise mais cuidadosa do desenvolvimento autônomo da colônia, ou da negociação, resistência e acomodação existentes entre os interesses metropolitanos e os coloniais. Se o trabalho de N ovais foi inovador ao compreender o comércio ea administração coloniais em seus aspectos mais intrincados e flexíveis, uma nova geração de historiadores compreen deu as mesmas relações de forma menos antagônica.

U m modelo para os estudos de contrabando éo proposto pelo historiador argentino Zacarias M outoukias. Este historiador, que atua na França, estuda o comércio ilegal na Buenos Aires do século XVII como parte indissociável da sociedade colonial, na qual grupos com diferentes interesses cooperavam e competiam entre si, estabelecendo redes a partir de sua participação dentro de atividades ilegais. Com base nos argumentos de M outoukias, defendo que o contrabando foi incorporado pela organização jurídica, econômica e social do império, que afirmava enão contradizia a autoridade real. Assim como N ovais e M outoukias, compreendo o contrabando como al go inerente à economia do Atlântico pré-moderno, atuante em todos os aspectos da sociedade luso-brasileira, assim como em qualquer outra parte da Europa, África e das Américas. Qual foi, então, o significado do comércio ilegal?

Se o contrabando era um fenômeno aceito e onipresente, como explicar o fato de que al gumas pessoas eram de fato processadas e condenadas? Para responder a tal questão, é necessário distinguir entre dois tipos de contrabando: 0 que era tolerado pelas autoridades e o que estava sujeito a uma condenação universal. 0 comércio ilegal tolerado era um comércio controlado, permitido pelas mesmas pessoas cujas funções oficiais pressupunham exatamente combatê-lo. Em outras palavras: era mais importante quem praticava o comércio ilegal e não quanto ele era praticado, ou seja, a qualidade vinha antes que a quantidade. Ao analisar por que algumas pessoas eram perseguidase outras não, procuro demonstrar onde reside a fronteira entre a tolerância e a condenação, indicando que tais limites eram muito mais definidos pelo status dos envolvidos do que por questões éticas ou morais. Assim sendo, o que 
determinava o status, coletiva ou individualmente? 0 status pode ser examinado em três diferentes níveis: em primeiro lugar, o internacional, isto é, a negociação realizada em uma esfera de Estado visando a envolver-se em atividades ilegais; em segundo lugar, os meios metropolitanos para influenciar o fluxo do comércio ilegal e, por fim, o interesse regional em colônias e na formação de alianças para perseguir e regulamentar o comércio ilegal.

Diplomatas e oficiais portugueses preocupavam-se muito com a economia política do contrabando. Seus despachos e diários são uma chave para se entender os pensamentos dos contemporâneos a respeito do comércio ilegal, especialmente quanto ao privilegiado porto do Rio de Janeiro. Os diplomatas estrangeiros exploravam o que percebiam ser a posição relativamente fraca que Portugal sustentava em relação à Europa, já que o menor país ibérico era militar e economicamente dependente de todas as outras nações para sua sobrevivência. Portugal era constantamente ameaçado de ocupação pela vizinha Espanha, e importava produtos básicos - como alimentos e têxteis para atender à demanda das colônias.

Essa posição precária possibilitou que os diplomatas estrangeiros fizessem negociações para que suas nações ingressassem no comércio ilegal. ${ }^{3}$ Em troca de auxílio militar e econômico, Portugal foi forçado a tolerar a incidência de comércio ilegal por parte de estrangeiros. Este fato levanta a questão: 0 que significava a legalidade ou a ilegalidade no comércio?

O comércio ilegal possuía duas faces: atividades comerciais, que eram completamente proibidas, e a evasão de impostos pagos sobre produtos. As duas maiores regras para o comércio dentro do império português eram de que todo o comércio de e para as colônias portuguesas, especialmente o Brasil, deveria passar por Portugal, e que todas as exportações de ouro de Portugal para nações estrangeiras eram proibidas por lei. Essas exportações de ouro eram uma parte essencial da economia portuguesa, pois o ouro equilibrava a balança comercial de Portugal em relação à maior parte dos países europeus e, assim, as autoridades portuguesas procuravam impedir o comércio direto com o Brasil a todo custo. Entretanto, os mercadores privados de nações que apoiavam Portugal, como Inglaterra e H olanda, gozavam de maiores privilé gios tanto em Portugal quanto nas ilhas do Atlântico. Tais privilégios Ihes proporcionavam maior facilidade para ingressar em atividades legais e ilegais por intermédio de mercadores portugueses. Por exemplo, mercadores de nações estrangei ras eram julgados por seus próprios magistrados, a quem mantinham por meio de um salário. As nações assim privilegiadas poderiam obter descontos na al fândega e possuíam liberdade de credo. Já os mercadores franceses tinham muitos problemas, visto sua nação estar envolvida em várias guerras contra Portugal. 
$\mathrm{N}$ a regulamentação do comércio ilegal, Portugal concedera diversos privilégios a outras nações. U ma dessa concessões previa que um paquete poderia sair de Falmouth (Grã-Bretanha) rumo a Lisboa e vice-versa, isento de ser revistado. Na prática, isto permitia o transporte de ouro para a Inglaterra. As nações que militarmente apoiavam Portugal e que conseqüentemente eram favorecidas - como Inglaterra e H olanda - e possuíam os privilégios mais extensivos do que, como mencionado, a França. Em outras palavras, essas nações exigiam o direito de atuar no comércio ilegal em Portugal de e para suas colônias em troca da proteção militar que proporcionavam. Além disso, autores estrangeiros afirmavam que a pretensa superioridade moral de suas nações sobre um país "atrasado" como Portugal era tamanha que legitimava ações declaradamente ilegais ou práticas comerciais questionáveis. Alegações de "indolência" não eram incomuns, como a do viajante inglês Barrow relativa à população do Rio de Janeiro em 1801:4

Eles são muito indolentes, muito invejosos e supersticiosos. 0 dia é dividido entre o sono e a cerimônia, o que não possibilita os prazeres do convívio social. $\mathrm{Na}$ verdade, as mentes da massa do povo não são suficientemente cultivadas para que se sinta apreço por eles; pois é verdade, como um grande moralista observou, que "sem inteligência o homem não éum ser social, é apenas gregário.

Estas acusações de "indolência" eram extremamente importantes, porque forneciam aos britânicos a legitimação para conduzir atividades consideradas ilegais segundo as leis daquelas nações "atrasadas".

As disputas comerciais existentes na Europa eram transplantadas ao teatro do N ovo M undo. Com o objetivo de ganhar controle sobre as atividades comerciais legais e ilegais, as autoridades brasileiras confiscaram cerca de vinte naus estrangeiras por realizarem comércio direto com a América portuguesa. ${ }^{5}$ Em certos casos, essas naus eram libertadas após vários anos de ações legais. Em outras circunstâncias, as confiscações eram objeto de negociação no campo diplomático, como no caso do navio holandês Dom Carlos, confiscado no Rio de J aneiro em 1725. Embora a Casa da Suplicação em Lisboa tivesse declarado que o confisco era legal, o rei permitiu a libertação da embarcação por meio do perdão real. Porém, o perdão trazia importantes restrições, pois os Estados holandeses deveriam primeiro fazer oferecer compensações por todos os navios portugueses que haviam sido confiscados na costa africana. Como os choques entre os governos português e holandês nunca foram resolvidos, a questão permaneceu aberta pelo restante do século. Como no caso do Dom Carlos, esses confiscos ocorreram mais freqüentemente durante períodos de disputas entre Portugal e nações estrangeiras. Sob al ega- 
ções falsas ou verdadeiras, muitas naus estrangeiras navegavam rumo aos portos brasileiros. M esmo visitantes conhecidos, como o capitão James Cook e sir J oseph Banks, dedicaram-se ao comércio ilegal durante sua estada em portos brasileiros. ${ }^{6}$ Geralmente os mestres dos navios estrangei ros seguiam a prática de permitir que as autoridades portuárias locais regulamentassem suas atividades, por vezes contra a política oficial portuguesa. Quando os mestres dos navios não aceitavam esses costumes, oficiais "zelosos" viam-se "obrigados" a aplicar a legislação anticontrabando, e os navios poderiam enfrentar sérios problemas.

Embora as autoridades portuguesas protestassem contra o comércio ilegal em seu território, incentivavam as transações comerciais ilegais entre Portugal e a América espanhola. 0 comércio com os territórios hispânicos através da Colônia do Sacramento era considerado positivo, pois trazia prata. Além disso, por meio de uma ocupação "virtual" e econômica, tanto os legisladores portugueses quanto os espanhóis buscavam obter a posse das terras disputadas. Em outras palavras, os portugueses e outros homens de Estado viam o contrabando com bons olhos desde que este atendesse aos interesses econômicos e políticos de sua terra natal. ${ }^{7}$

A administração colonial teve papel decisivo na regulação do comércio 402 ilegal. A administração do império português era caracterizada por um alto grau de centralização, especialmente eficiente em cidades portuárias como 0 Rio de Janeiro. Na prática, a política das Câmaras M etropolitanas dominava as regulações econômicas. A Coroa mantinha sua administração sob controle manipulando sua estrutura com uma série de fiscalizações e balanços, para que os administradores controlassem uns aos outros. ${ }^{8}$ Tais fiscalizações vigoravam tanto no nível das hierarquias administrativas quanto no dos oficiais individuais. 0 deslocamento da jurisdição era uma estratégia adotada pela Coroa. Os administradores eram de origens nobres (ou menos nobres), alguns haviam nascido em Portugal e outros eram nativos do Brasil. Essas duas circunstâncias, riqueza e nascimento, eram exploradas e manipuladas pela Coroa. Por exemplo, os nascidos no Brasil poderiam herdar seus cargos, enquanto os portugueses eram escolhidos pelo rei; outros ainda poderiam ganhar e vender cargos graças a serviços prestados, por exemplo, no plano militar.

$N$ ão surpreende que muitos conflitos tenham surgido entre os administradores. A jurisdição concedida pelo rei ao administrador significava que parte do comércio ilegal estaria sob seu controle. 0 rei era o único árbitro dos conflitos existentes, pois as jurisdições eram confusas e sobrepostas; e o rei punha essa política em ação por meio da legislação e de decretos, cartas e patentes reais. 0 arbítrio real era essencial para que se determinasse 0 alcance da jurisdição de um indivíduo ou de um órgão do governo. Ao alterar essas 
jurisdições, o rei poderia manipular aqueles que poderiam exercer controle legítimo, e assim participar e se beneficiar de sua própria fatia do comércio ilegal. Portanto pode-se interpretar que o papel da legislação era não apenas decretar punições para quando se infringia a lei, mas também confirmar a autoridade real. Leis repetitivas, ou leis que não eram aplicadas não significavam - de acordo com essa visão - uma fragilidade, mas sim a arbitrariedade e a dinâmica do poder bruto controlado pelo rei como única fonte de legitimação e de autoridade absoluta.

Ao longo do século XVIII, diferentes políticas reais levaram a várias reformas na administração carioca e em sua jurisdição sobre o comércio legal e ilegal. Vários setores da administração controlavam diferentes aspectos das atividades comerciais. Por exemplo, quando um navio estrangeiro se aproximava da baía de Guanabara, um grupo ia a bordo levando um juiz apontado pela Coroa, um intérprete, um médico, dois oficiais militares de alto escalão e dois del egados das autoridades portuárias. A pós o desembarque, o capitão deveria visitar o governador ou o vice-rei, enquanto a nau era vigiada por soldados indicados por oficiais da alfândega. A pós um interrogatório completo, esses oficiais e soldados aproveitavam a ocasião para se impor como intermediários em quaisquer atividades comerciais. $A$ autoridade local sobre as atividades comerciais estava em seu auge no início do século XVIII, quando a Câmara M unicipal controlava a grande parte dos impostos. ${ }^{9} \mathrm{Em} \mathrm{1733}$, após as disputas entre o governador Luís Vahia M onteiro e os membros da Câmara terem atingido seu ápice, a Câmara M unicipal perdeu grande parte de seu poder sobre a alfândega. 0 provedor da fazenda e o juiz ouvidor da alfândega tornaram-se figuras chave na administração do porto. No Rio de Janeiro, eles tanto compravam quanto herdavam seus cargos, e eram nativos do Brasil. A partir de 1753, sua posição foi cada vez mais desafiada pelo estabelecimento recente da Relação do Rio de Janeiro. Os juízes da Suprema Corte começaram a infringir as jurisdições do provedor da fazenda e do juiz ouvidor da alfândega, até tomá-las em suas mãos respectivamente em 1769 e 1786. Como os juízes superiores eram em sua maioria nascidos em Portugal, e indicados pelo rei para um mandato fixo de seis anos, a regulação das práticas comerciais tornou-se menos local. Ainda assim, esse sistema também se adaptou, pois os juízes da Suprema Corte podiam desposar brasileiras, e também cresceu o número de oficiais nascidos no Brasil.

A sociedade colonial era fortemente estratificada. Andando pelas ruas do Rio de Janeiro, era possível distinguir diretamente o status das pessoas por sua aparência e trajes. ${ }^{10} \mathrm{~N}$ os desfiles, datas religiosas e festividades públicas, 
em ocasiões públicas e privadas e mesmo na morte, os códigos de vestimenta indicavam esse status. Todos os habitantes - de escravos africanos até o vice-rei - procuravam indicar sua posição social tornando-se membros de irmandades, ordens-terceiras, da Santa Casa da M isericórdia, ou pelo trabal ho em qualquer órgão público. Era esperado que os habitantes do Rio de Janeiro se vestissem e se comportassem de maneira adequada à sua posição (qualidade), pois esse sistema de desigualdade estava institucionalizado pela lei e pelo costume.

As atividades econômicas eram tão estratificadas quanto os desfiles. 0 comércio não estava aberto a todos, pois muitos setores da economia eram monopolizados. Essas áreas incluíam o monopólio do sal, da caça à baleia, da pesca costeira, da importação de vinho e da exportação de madeira e fumo brasileiros. As atividades econômicas eram tão restritas quanto as sociais: as pessoas poderiam tomar parte nelas segundo suas origens sociais e culturais. Como M ary Karasch e Luciano Figueiredo demonstraram, profissões como as de vendedores de certos produtos baseavam-se em gênero e etnias específicos. ${ }^{11}$

O espaço urbano era importante na determinação dequem regulava quais partes do comércio. 0 governador, os militares, os oficiais da alfândega e os 404 conselheiros municipais possuíam jurisdição sobre diferentes áreas, designadas segundo o comércio realizado. A área mais disputada era o cais, sobre 0 qual todos os quatro grupos buscavam controle. N aquele espaço, ambulantes, mercadores, pescadores, soldados, marinheiros de naus costeiras, marinheiros estrangeiros e oficiais buscavam sua parcela na economia ilegal. 0 controle exercido por um administrador sobre esse ambiente podia ser facilmente convertido em uma renda extra. Por exemplo, os pescadores que chegavam às praias do Rio de Janeiro com o fruto de sua pesca deveriam pagar uma décima parte a quem os contratava, cobrança esta que cabia à guarda local. Em 1733 surgiu uma queixa de que esses guardas estariam obrigando os pescadores a vender sua pesca a eles, que então agiam como intermediários livres de impostos. ${ }^{12} \mathrm{M}$ as nenhuma autoridade possuía poder ilimitado, pois o excesso de controle e abuso de poder por parte dos oficiais levavam a um crescimento dos preços e das queixas. Ou a situação tornava-se uma espécie de modus vivendi, um código não escrito que determinava o que as pessoas podiam ou deviam fazer de acordo com seu status, ou em raras ocasiões houve murmuração entre a população, ou, ainda, ela se rebelava. Um excesso de queixas poderia levar a graves conseqüências para o administrador envolvido. Ainda assim, apenas em ocasiões muito raras esse administrador era processado até o fim.

As fronteiras da tolerância para com o comércio ilegal dependiam da po- 
sição dos envolvidos. Os de maior status eram os mercadores que enviavam grande quantidade de produtos em suas embarcações, administradores importantes, clérigos e oficiais militares. Estes dificilmente eram processados e, se o fossem, raramente o processo corria atéseu final. A punição, quando aplicada, indicava que a pessoa havia não apenas infringido a lei mas, igualmente, cruzado a linha que determinava o que era ou não um comportamento "aceitável".

A hierarquia existente no comércio era reproduzida pelos processos legais. Segundo a lei, diferentes penas eram aplicáveis a nobres, clérigos ou homens comuns, e ter posses e boas conexões determinava o grau de punição. Entre essas gradações, era possível conseguir uma prisão mais confortável ou mesmo uma prisão domiciliar, obter a opinião de médicos atestando 0 impacto negativo da prisão para a saúde do acusado e obter, até mesmo, a possibilidade do perdão real.

Segundo Foucault, o significado da punição alterou-se entre o início e o final da Era M oderna. 0 aprisionamento existia, mas colocar al guém na cadeia não era considerado uma punição, e sim uma ação preventiva com vistas a manter a pessoa fora da sociedade. Entretanto, o processo de encarceramento era em si uma punição, que consumia tempo e dinheiro..$^{13} \mathrm{~A}$ resposta a petições enviadas ao rei em Portugal poderia, com sorte, ocorrer no prazo de um ano, mas usual mente essas petições terminavam em al guma instituição burocrática como o Consel ho U Itramarino e poderiam esperar anos, ou mesmo décadas, até receberem uma resposta. A pós a petição, a Câmara poderia pedir por um parecer no Brasil, o que demorava mais um ano; e se o ConseIho U Itramarino não chegasse a um acordo, uma segunda (ou terceira) opinião por parte de outros administradores em Portugal ou no exterior era solicitada. Todas essas petições custavam tempo e dinheiro e pessoas menos influentes poderiam vir a morrer na prisão. Por exemplo, o vice rei veio a saber em 1779 que um soldado estivera encarcerado por 27 anos, embora tivesse sido condenado a apenas um exílio de quatro anos em Santa Catarina. A falta de condições financeiras do prisioneiro impediu sua libertação. ${ }^{14}$

Por outro lado, dificilmente os mais poderosos e bem relacionados eram aprisionados, ou mesmo processados. U m caso notável foi o de José de Torres, um comerciante de Salvador que estabel ecera comércio ilegal com os holandeses na costa oeste da África. M esmo tendo o astuto comerciante sido denunciado várias vezes, e mesmo havendo claras evidências de suas atividades de contrabando, a Coroa sempre conseguiu a liberdade para ele. Torres recebeu tal tratamento devido a serviços prestados à Coroa: el e havia construído com sucesso uma fortaleza no oeste da África, o que lhe deu uma espécie de passe livre. Outro caso semelhante foi o de $M$ anoel $N$ unes Viana, nas $M$ inas 
Gerais das primeiras décadas do século XVIII. Dada a ausência de qualquer controle metropolitano, o rei deu a Viana o cargo de capitão-mor, mesmo ciente de que ele se dedicava a vários atos passíveis de punição. 0 fato de que Viana traria a autoridade real ao sertão era mais importante do que a punição a seus crimes, ou seja, os serviços prestados por Torres eViana eram mais importantes que suas atividades ilegais. ${ }^{15}$ Em outras ocasiões, a Coroa não tinha condições para punir oficiais muito bem relacionados. U m exemplo extremo foi o de dom Lourenço de Almeida, que acumulara uma fortuna lendária após seus cargos como governador de Pernambuco e de M inas Gerais. Suas fortes ligações com a Corte por meio de laços de matrimônio e clientelismo impediam que quaisquer ações, legais ou não, fossem tomadas contra ele. Cerca de sessenta anos mais tarde, quando o vice rei conde de Resende retornou para casa após seu mandato no Rio de Janeiro, as denúncias contra seu comportamento não causaram surpresa. 0 chanceler da Suprema Corte observou sutilmente que uma ação urgente contra o comércio ilegal consistiria em obedecer a lei de 1612 risca, vale dizer, que um governador não poderia favorecer os filhos (como o fizera Resende) com sua posição no governo. ${ }^{16}$ M as o apreço do príncipe regente não seria abalado por denúncias na colônia, e Resende obteve até mesmo uma licença especial para que sua bagagem 406 não fosse inspecionada quando de sua chegada a Lisboa. ${ }^{17}$ Esse tratamento preferencial chamava a atenção da população local, e até mesmo um observador estrangeiro como Barrow não se furtou a fazer observações sobre o corrupto vice-reinado: o vice-rei Ihe parecia um grande sovina cujo único objetivo era acumular uma fortuna principesca. ${ }^{18}$

Seria incorreto supor que todos aqueles dotados de poder estavam acima da lei. Felisberto Caldeira Brant, o famoso contratador de diamantes que se envolveu em inumeráveis negócios ilegais, levou suas atividades a tal ponto que nem mesmo suas relações pessoais e sua fortuna foram suficientes para protegê-lo. Brant foi aprisionado e enviado de forma secreta para Lisboa, onde veio a falecer na prisão do Limoei ro. ${ }^{19}$ Se Brant faleceu à espera de um processo, criminosos mais poderosos que sobreviveram ao processo criminal tiveram mais sorte. U m exemplo disto ocorreu com o famoso ourives Francisco Xavier Telles, que confessou sob interrogatório praticar o contrabando de ouro e diamantes. Neste caso, porém, o sistema dobrou-se aos poderosos, pois mesmo com provas cabais o ourives obteve em Portugal o perdão real e a liberdade.

Controlar o trafico ilegal era diferente de participar diretamente de atividades de contrabando. A lei proibia governadores ealtos oficiais de se dedicarem a atividades comerciais. Entretanto, como não raro vice-reis e governadores eram membros de uma nobreza portuguesa pobre, esperava-se que 
enriquecessem em sua estada no Brasil. ${ }^{20}$ Ao longo do século XVIII, o estigma negativo das atividades comerciais perdeu força, pois era possível até conseguir o título de nobreza por meio do comércio. Para conseguir ao menos uma aparência de decência, governadores com títulos de nobreza realizavam suas transações financeiras com o auxílio de intermediários. Possuir "ligações perigosas", como ocorria com ricas potestades como dom Lourenço de Almeida, era al go comum para os nobres. Suas ações originaram muitos versos satíricos por parte de seu conterrâneos letrados. ${ }^{21}$ M as como "justiça poética", até mesmo os poetas envolviam-se com atividades ilegais. Gonzaga, o ilustre autor e ouvidor da Inconfidência M ineira, autor das satíricas Cartas Chilenas, possuía fortes ligações com a elite mineira e muitas vezes impediu que seus parentes fossem processados por contrabando.

A idéia de que o comércio ilegal era imoral e errado era vista com perplexidade. Se o comércio ilegal era por vezes estimulado pela Coroa portuguesa, como no caso do comércio com o rio da Prata, como poderia ser considerado imoral? Para responder a tal questão, é essencial retornar a outra questão básica: como o contrabando era definido?

O dicionário Oxford definia "contrabando" como "atividadesilegais contráriasà lei ou a proclamações", termo originado no latim tardio, ecomo "qualquer coisa proibida de ser exportada ou importada". Esta definição neutra torna-se mais tendenciosa quando se lê que “(...) mas a forma atual de contrabando parece provir diretamente do tráfico de possessões da Espanha em cerca de 1600". ${ }^{22} \mathrm{~N}$ os exemplos utilizados pelo dicionário, torna-se óbvio que, dadas as circunstâncias, um contrabandista deixa de seu um herói e passa a ser um vilão. Se durante a Revolução Americana um contrabandista era um "verdadeiro filho de M assachusetts", no final do século XIX um autor irmanou os contrabandistas a "vagabundos e ciganos". Tais definições demonstram que duas questões estão em jogo: quem estava envolvido e qual o destino do contrabando. 0 contrabando possui uma conotação negativa dentro do próprio país, como por exemplo a Inglaterra - quando é perpetrado pelos escal ões mais baixos da sociedade. No entanto, no caso das colônias britânicas na América, os colonos em busca da independência consideravam o comércio ilegal como "patriótico". Contrabandear para a América espanhola até mesmo originou a palavra, como se 0 ato do contrabando fosse algo próprio apenas daquelas regiões.

Autores portugueses e brasileiros também marginalizaram os contrabandistas. Os vice-reis eram julgados com rigor e condenados. Segundo o conde de Resende, ele próprio acusado de atividades ilegais, os contrabandistas eram "pessoas perversas" que colocavam seus próprios interesses acima dos do Estado. ${ }^{23}$ Luís de Vasconcellos e Souza chamou os contrabandistas do sul de "in- 
di víduos vagos e dispersos, que vivem segundo a lei da natureza, sem disciplina e sem religião". ${ }^{24}$ Em outras palavras, pessoas fora do controle do governo e da igreja e, portanto, imorais. 0 marquês de Lavradio, predecessor de Vasconcellos e Souza, acreditava que a instrução seria uma solução para o problema. Em sua opinião, "esta qualidade de gente que são a peste dos Estados, não estando eles acostumados senão a huma relaxação a mais escandaloza, bem consedero que armará contra mim o espirito destas gentes que vivião sem conhecimento, nem respeito as Leys" ${ }^{25}$ Assim, de acordo com o honesto Lavradio, também os que deveriam aplicar a lei eram culpados por não ensinar o caminho correto. Esse tema era recorrente nos escritos pessoais e oficiais de Lavradio, pois ele objetivava diferenciar-se de seus predecessores para conseguir, mais tarde, favores reais.

O discurso oficial da legislação portuguesa destacava especialmente os comissários volantes como agentes de atividades ilegais, pois eram contratados pelos mercadores britânicos em Lisboa para realizar comércio no Brasil. Considerados como "forasteiros" dentro do comércio normal, eram condenados nos mais duros termos. Para servir de exemplo para os estrangei ros que apoiavam esses comissários, uma lei de 1757 condenava esses contrabandistas, que traziam tantos danos ao comerciante honesto, "à abjeção e desprezo de todas as nações civilizadas". ${ }^{26}$

Tanto a legislação oficial quanto as cartas oficiais dos vice reis ao secretário de Estado descreviam os contrabandistas como pessoas de baixa estirpe, oriundos dos piores setores da sociedade. Os acusados por esse crime não eram o oficial venal ou o mercador distante, mas os forasteiros. Eles deveriam ser processados, pois ultrapassavam sua posição na sociedade. Essa, a visão oficial de comércio ilegal. Entretanto, os homens da colônia revidavam com sátiras e mesmo com relatos publicados sobre a economia e a sociedade da América portuguesa. U m dos relatos mais neutros sobre a economia brasileira colonial foi o do jesuíta Antonil, publicado em 1711. Antonil defendia 0 Estado e fazia várias observações sobre impostos e ilegalidade. Em um capítulo, Antonil defendeu, utilizando autores seculares e religiosos, o direito de o rei de coletar o quinto, argumentando que o solo era patrimônio do rei e, portanto, cabia ao rei decidir quem trabalhava nele; em troca, os mineiros pagavam o quinto para financiar os gastos da República e a manutenção da re ligião. ${ }^{27}$ Assim, ao rei era dado o poder de punir aqueles que rompiam esse contrato.

Para Antonil, os contrabandistas eram pequenos mercadores que corriam o risco de serem apanhados por duvidosos administradores. Em uma descrição acerca do fumo, o padre jesuíta afirmava que muitas famílias eram arruinadas quando o pater familias era apanhado praticando contrabando, 
sendo a pena de cinco anos de exílio para Angola alta demais a se pagar para os pequenos lucros conseguidos com o comércio ilegal. 0 contrabandista poderia ser inventivo eengenhoso - muitos escondiam o fumo noslugares mais inusitados - , mas os riscos eram muito altos e o administrador era "dos mesmos ministros que como Argos de cem ol hos vigiam, quando não são juntamente Briarêos de cem mãos para receber". ${ }^{28}$

Sendo um padre, Antonil silenciava de uma forma incomum sobre os aspectos morais do comércio ilegal. N este sentido, os contrabandistas não eram aqueles párias da sociedade como os vice-reis e a legislação defendiam, mas sim pais de família aos que se deveria prevenir sobre o preço a pagar caso fossem apanhados em suas atividades. Q uanto aos mineiros, que contestavam os direitos da Coroa de coletar impostos depois que o ouro havia sido extraído com tanto esforço, Antonil rapidamente afirmava que a I greja estava do lado do rei. Entretanto, a venalidade dos oficiais, seculares ou não, em nada auxiliava a afirmar os direitos reais.

A condenação moral direta aos contrabandistas era rara. A legislação portuguesa chamava o comércio ilegal de "pernicioso", não porque fosse imoral, mas porque o contrabandista roubava as riquezas do rei ou fraudava os bens do povo, ao mesmo tempo em que prejudicava o bom andamento do comércio honesto. M as se o contrabando não prejudicasse o tesouro real nem fosse complementar a atividades comerciais normais - como no comércio com Buenos Aires - , então era tolerado e até mesmo estimulado. Em outras palavras, por vezes quebrar a lei era visto como muito positivo.

A condenação moral não constava nem do discurso oficial nem dos escritos religiosos. A penas no âmbito não- oficial, de forma encoberta, tais opiniões eram proferidas. U ma importante obra marcada pela condenação moral era ArtedeFurtar. Taisquestões eram tão sensíveis quetanto o autor quanto a data de publicação de Arte de Furtar tiveram que ser omitidos para que o livro fosse impresso. Escrito original mente em meados do século XVII, publicado apenas em 1742 (embora se al egasse que o fora em 1652), a obra trazia a falsa autoria do célebre padre e orador do século XVII, Antônio Vieira. Dentro da velha tradição de 0 Soldado Prático, deDiogo de Couto, quelidava com a venalidade da Índia portuguesa do século XVII, o autor de Arte de Furtar expõe as maneiras pelas quais o povo podia roubar o tesouro real..$^{29} \mathrm{Afirma}$ que ladrões podiam ser encontrados em toda a sociedade, mas, diferentemente do que se dizia na legislação real e nos relatórios dos vice-reis, esses ladrões não estavam apenas entre os párias da sociedade. Pelo contrário, a obra afirma que o rei espanhol era um ladrão, assim como os membros da al ta sociedade, pois quanto mais alto se sobe, mais se pode roubar. 0 livro termina com uma lição moralista e religiosa para os poderosos: você pode roubar o que 
quiser, obter todos os títulos imagináveis, mas morrerá tão nu quanto nasceu. Os pecadores vão para o inferno, e a fortuna deixada para as massas após a mortenão impedirá esse fato.

Ao lermos o discurso não-oficial sobre a ilegalidade, podemos inferir que os homens da colônia encaravam a ambivalência entre crime e contrabando com uma dose de humor. As sáti ras eram a arma mais poderosa contra os pecados da administração. Como se pode imaginar, não muitas foram publicadas, principalmente no século XVIII. As obras restantes são atribuídas a Gregório de M atos e ao poeta inconfidente Tomas A ntónio Gonzaga, quelidou com a sociedade viciada indo do comportamento sexual condenável à corrupção em massa. ${ }^{30}$ Tais poemas satíricos vieram à luz apesar do controle oficial, e eram escritos pelos próprios oficiais. Gonzaga era ouvidor em Ouro Preto, de M atos um desembargador do Tribunal Eclesiástico do Brasil, e seus leitores provavelmente eram da mesma estatura social.

Dentro de um estilo pessoal, Gonzaga e de M atos podiam criticar a corrupção e o contrabando, especialmente de seus inimigos. Seus poemas nos lembram das muitas denúncias enviadas por oficiais contra seus colegas, resistindo não tanto contra o rei português ou o sistema colonial, mas contra seus próprios rivais.

$410 \quad 0$ contrabando permanece um fenômeno ambivalente. 0 fracasso em condenar o comércio ilegal como algo imoral nas fontes oficiais elegislativas e sua ampla aceitação dentro da sociedade brasileira fizeram do contrabando um crime ilusório. 0 contrabando era tolerado quando praticado por si próprio, e condenável quando praticado pelo outro. Tanto o comércio legal quanto o ilegal eram desiguais e hierárquicos, pois ocorriam em um mercado e em uma sociedade não-livres. Praticar contrabando era - e permanece sendo - parte de nossa sociedade, seja no Brasil do século XVIII, na H olanda ou nos Estados U nidos, hoje. Sua rel evância reside não na existência do comércio ilegal em si, mas no fato de que podia ser regulado, tanto pela sociedade quanto por seus representantes. $O$ aumento no número de confiscos e denúncias do fim do século XVIII e início do XIX demonstraram a perda desse controle e a necessidade de uma reforma profunda na sociedade colonial.

\section{NOTAS}

${ }^{1}$ Este projeto de pesquisa foi financiado pela Fundação Luso-Americana para o desenvolvimen-
to (Lisboa, Portugal), Prins Bernhard/Reiman de Bas Fonds (Amsterdam/The N etherlands),
The John Carter Brown Library (Providence, Rhode Island, U.S.A.), eThe John H opkins U ni-
versity (Baltimore, M aryland, U.S.A.).
${ }^{2}$ A historiografia abaixo cita: CHRISTOLOW, Allan. “Great Britain and the Trades from Cadiz 
and Lisbon to Spanish America and Brazil, 1759-1783". In H ispanic American H istorical Review [HAHR], 1947, 27:1, pp. 2-29; para uma discussão historiográfica, vide: KAGAN, Richard L., "Prescott's Paradigm: American H istorical Scholarship and the Decline of Spain". In American H istorical Review, 101, 1996, pp. 423-446; SIDERI, Sandro. Trade and Power. Informal Colonialism in Anglo-Portuguese Relations. Rotterdam; Rotterdam U niversity Press, 1970; NOVAIS, Fernando A. Portugal e Brasil na Crise do Antigo Sistema Colonial (1777-1808) . 4ª ed., São Paulo: Editora H ucitec, 1986; FRAGOSO, João Luís Ribeiro. H omens de Grossa Aventura: Acumulação e Hierarquia na Praça M ercantil do Rio de Janeiro. Rio de Janeiro, Arquivo Nacional, 1992; FRAGOSO, João \& FLORENTINO, M anolo. 0 Arcaísmo como Projeto. M ercado Atlântico, Sociedade Agrária, e Elite M ercantil no Rio de Janeiro, c. 1790 - c.1830. 2ae ed., Rio de Janeiro: Sete Letras, 1993; BICALH O, M aria Fernanda Baptista. A Cidade e o Império: o Rio de Janei ro na Dinâmica Colonial Portuguesa. Séculos XVII eXVIII. Tese de doutorado, Universidade de São Paulo, 1997; FIGUEIREDO, Luciano. 0 Avesso da M emória. Cotidiano e Trabalho da M ulher em M inas Gerais no Século XVIII. Rio de Janeiro: José Olympio, 1993; FURTADO, Júnia Ferreira. O Livro da Capa Verde. 0 Regimento Diamantino de 1771 e a Vida no Distrito Diamantino no Período da Real Extração. São Paulo: Annablume, 1996; ROM EIRO, Adriana. "Confissões de um Falsário: as Relações Perigosas de um Governador nas M inas. In H istória: Fronteiras. XX Simpósio Nacional da ANPUH, São Paulo: ANPUH, 1999, vol. 1, pp. 321-337; M OUTOUKIAS, Zacarias. "Power, Corruption, and Commerce: The M aking of the Local Administrative Structure in Seventeenth Century Buenos Aires". In HAH R, 1988, 68:4, pp. 771-801; Contrabando y Control Colonial, Buenos Aires y el Espacio Peruano en el Siglo XVII. Buenos Aires: Bibliotecas U niversitárias, 1988; “U na forma de O posición: el Contrabando”. In GANCI, M assimo \& ROM ANO, Ruggiero. (org.). Governare il M ondo. L'Imperio Spagnolo dal XV al XIX Secolo. Palermo: Società Siciliana per la Storia Patrial, 1991, pp. 333-368; “Reseaux Personelles et Autorité Coloniale: les N égociants de Buenos Aires au XVIII esiècle". In Annales E.S.C. 1992, 4/5: pp. 889-914.

${ }^{3}$ PIJN ING, Ernst. "Passive Resistance: Portuguese Diplomacy of Contraband Trade during king John V's Reign (1706-1750)". Arquipélago - História 20 série, II (1997), pp. 171-191; sobre os problemas da França nas ilhas do Atlântico, vide: Despacho do cônsul francês em Fayal, M r. de H arrangue, 29 março, 1724, Archives Nationalles (Paris) [AN P], Affaires Étrangères [AE], B/I/487, fl.41r-44v, LABOURDETTE, Jean-François. La N ation Française a Lisbonne de 1669 à 1790 entre Colbertisme et Liberalisme. Paris, Fondation Gulbenkian, 1988, pp. 153-158.

4 "They are very indolent, very jealous of each other, and very superstitious. The day is divided between sleep and ceremony, and mutual distrust is but ill suited for the pleasures of social intercourse. In fact, the minds of the mass of the people are not sufficiently cultivated to feel any relish for them; for it is a certain truth, as a great moralist has observed, that "without intelligence man is not social, he is only gregarious". BARROW, John. A Voyage to Cochinchina in the Years 1792 and 1793 (London: printed for T. Cadell and W. Davis, 1806) 97.

${ }^{5}$ As fontes para essas afirmações constam da correspondência diplomática dos embai xadores francês e britânico e o representante do governo holandês, encontradas em diferentes arquivos: Archives N ationalles Paris [ANP], Public Record Office, Algemeen Rijksarchief, e M inistério de Negócios Estrangeiros [M .N.E.] no Arquivo N acional da Torre do Tombo [ANTT], assim como em papéis avulsos [p.a.] do Rio de Janeiro no Arquivo Histórico U Itramarino [AHU] e na Seção Colonial [S.C.] do Arquivo Nacional do Rio de Janeiro [ANRJ]. 0 número é extremamente 
baixo. A título de exemplo: em Cartagena de las Indias e arredores, nada menos que 413 embarcações foram confiscadas no período entre 1715 el761. Vide: GRAHN , Lance. The Political Economy of Smuggling. Regional informal Economies in Early Bourbon N ew Granada. Boulder, Westview Press, 1997, appendix 1.3; Dom Luís da Cunha, Instrucções I néditas de Dom Luís da Cunha a M arco António de Azevedo Coutinho. AZEVED O, Pedro de. (org.). Coimbra: Imprensa da Universidade, 1929, p. 152, Representação do representante do governo holandês em Lisboa, Smissaert, para a rainha, 25 março, 1782, ANTT, M.N.E., Arquivo Central, caixa 507; os historiadores holandeses tendem a subestimar o papel dos traficantes luso-brasileiros de escravos na Costa da M ina: HEIJER, H enk den. Goud, I voor en Slaven, Scheepvaart en H andel van de T weede Westindische Compagnie op Afrika, 1674-1740. Zutphen: Walburg Pres, 1997, pp. 193-204.

${ }^{6}$ ALDEN, Dauril. Royal Government in Colonial Brazil. With a Special Reference to the Administration of the M arquis of Lavradio, Viceroy, 1769-1779. Berkeley: University of California Press, 1968, pp. 403-417; BANKS, Joseph. The Endeavour Journal of J oseph Banks 1768-1771. BEAGLEHOLE, J.C. (org.). Sydney: Halstead Press, 1962, 1:190.

${ }^{7}$ ALDEN. Royal Government. pp. 67-68; Despacho de Alexandre de Gusmão para o governador de Sacramento, Luís Garcia Bivar, January 20, 1749. In CORTESÃO, Jaime. Alexandre de Gusmão e o Tratado de M adrid. Rio de Janeiro: M inistério das Relações Exteriores, 1953, 2:1, pp. 288-290; CAM PBELL, D onald. "Reflexoens imparciaes sobre o trafico de escravatura entre as Colonias de Portugal e H espanha". 30 abril, 1802, AHU, Rio de Janeiro, p.a., caixa 199, doc. 6.

${ }^{8} \mathrm{Clarence} \mathrm{H}$ aring também contribuiu para a compreensão da administração metropolitana e colonial. Sobre o império espanhol, tais relações são mais bem descritas em: The Spanish Empire in America. 1a ed., 1947; reprint: San Diego: H arcourt Brace Jovanovich, 1985. Considero uma "armadilha weberiana" achar que a única causa de corrupção e venalidade seja a noção de que os administradores julgavam seus cargos como de posse privada; WEH LIN G, Arno e M aria José. "O Funcionário Colonial entre a Sociedade e o Rei," In DEL PRIORE, M ary. (org.). Revisão do Paraíso. Os Brasileiros e o Estado em 500 Anos de História. Rio de Janeiro, Editora Campus, 2000, pp. 144-145.

${ }^{9}$ BICALHO, M aria Fernanda Baptista. "As Representações da Câmara do Rio de Janeiro ao M onarca e as D emonstrações de Lealdade dos Súditos Coloniais, Séculos XVII eXVIII". In VIEIRA, (org.), O M unicípio no M undo Português, pp. 527-531, ALDEN, Royal Government, pp. 309-310; Alvará 3 março, 1770, AHU, Rio de Janeiro p.a., caixa 94, doc. 11, Portaria Luís de Vasconcellose Souza, 17 fevereiro, 1786, Arquivo Nacional Rio de Janeiro, Seção Colonial, caixa 496, pacote 3. Num primeiro momento, os pedidos para que juízes da Suprema Corte se casassem com habitantes locais foram abertamente negados: representação $M$ athias Pinheiro da Silveira para o rei, analisada em 13 janeiro, 1754, AHU, Rio de Janeiro, p.a., caixa 55, doc. 7. M ais tarde esses casamentos foram permitidos sem que se ao menos fosse apresentado o nome da futura esposa: representação Joaquim deAmorim Castro para o príncipe regente, analisada em 16 julho, 1805, AHU, Rio de Janeiro, p.a., caixa 222, doc. 42. Para um estudo aprofundado sobre a importância da "mestiçagem" na Suprema Corte de Justiça de Salvador, vide: SCHW ARTZ, Stuart B. Sovereignty and A uthority in Colonial Brazil, theH igh Court in Bahia and itsJudges, 1609-1751. Berkeley: University of California Press, 1973. Entre 1752 e 1808, cerca de 15\% dos juízes da Suprema Corte eram de nascidosnas colônias. WEH LING and WEH LING. "O Funcionário Colonial”. p.158.

${ }^{10}$ LARA, Sílvia Hunold. “Sedas, Panos e Balangandãs: o Traje de Senhoras e Escravas nas Cida- 
des do Rio de Janeiro e de Salvador (Século XVIII)". In SI LVA, M aria Beatriz Nizza da. (org.). Brasil Colonização e Escravidão. Rio de Janeiro: N ova Fronteira, 2000, pp. 178-191.

${ }^{11}$ KARASCH, M ary. "Suppliers, Sellers, Servants, and Slaves". In H OBERM AN, Louisa Schell and SOCOLOW, Susan M igden. Cities \& Society in Colonial Latin America. Albuquerque: University of New M exico Press, 1986, pp. 268-271; FIGUEIREDO, Luciano. Avesso da M emória. pp. 43-71.

12. Requerimento de pescador ao governador, 18 julho, 1731, despacho do governador Luís Vahia M onteiro, mesma data, ANRJ, S.C., cód. 87, fl. 158r. Fernanda Bical ho demonstrou que as disputas jurídicas aconteciam não somente sobre questões comerciais mas também de defesa. Para as políticas do espaço urbano no Rio de Janeiro, vide: BICALHO, M aria Fernanda Baptista. A Cidade e o Império: o Rio de Janeiro na Dinâmica Colonial Portuguesa, Séculos XVII eXVIII. Tese de doutorado, U niversidade de São Paulo, 1997, pp. 388-437, e seu “O U rbanismo Colonial e os Símbolos do Poder: o exemplo do Rio de Janeiro nos Séculos XVII eXVIII". In Estudos I beroAmericanos. PUC/RS, vol. 24, no 1, June, 1998, pp. 31-57.

13. FOU CAULT, Michel. Surveiller et Punir, N aissance de la Prison. 1aㅡ. ed., 1975; reimpresso SaintAmand, Bussière Camedans Imprimeries, 2000, pp. 267-273; HESPANH A, H istória de Portugal. Vol. 4, p. 246; SOUZA, Laura de M ello e. Desclassificados do Ouro. A Pobreza Mineira no Século XVIII. 3ạ ed., Rio de Janeiro: Graal, 1990, pp. 116-129; SILVEIRA, M arco António. 0 U niverso do Indistinto. Estado e Sociedade nas M inas Setecentistas (1735-1808). São Paulo: H ucitec, 1997, pp. 154-161.

${ }^{14}$ Parecer de Luís de Vasconcellos e Souza para M artinho de M ello e Castro, 23 setembro, 1779, AHU, Rio de Janeiro, p.a., caixa 120, doc. 69; VERGER, Pierre. Flux et Reflux de la Traite des Nègres entre le Golfe de Bénin et Bahia de Todos os Santos du Dix-Setième au Dix-N euvième Siècle. Paris and TheH ague, M outon, 1968, pp. 72-78.

${ }^{15}$ RUSSEL-WOOD, A.J.R. \& VIANA, M anuel Nunes. Paragon or Parasite or Empire? The Americas. Vol. 37, p. 4, April 1981, pp. 479-498; sobre d. Lourenço de Almeida, veja: ROM EIRO, Confissões de um Falsário. pp. 329-330, Despacho De M ontagnac ao secretário de Estado da França, 14 de abril de 1733, ANP, AE, B/I/666, fl.24r-249r e visconde de Santarém, Quadro Elementar das Relações Politicas e Diplomáticas de Portugal com as diversas Potencias do M ondo desde o Princípio da M onarchia até aos nosso Dias. Lisboa: Académia das Sciencias, 1842-1860, 5, cclxvii, fonte 33; sobre o conde de Resende, veja: Carta anônima para conde de Resende, Biblioteca Nacional do Rio de Janeiro [BNRJ], ms. 11,2,2.

${ }^{16} \mathrm{M}$ emorando de Luís Beltrão de Gouvea d'Almeida para o secretário de Estado visconde de Anadia, 16 abril, 1802, AHU, Rio de Janeiro, p.a., caixa 196, doc. 40.

${ }^{17}$ Despacho de Pedro de Sante da Silva para o secretário de Estado, 7 julho, 1802, AHU, Rio de Janeiro, p.a., caixa 201, doc.5.

${ }^{18}$ BARROW, A V oyage to Cochinchina. p. 97.

${ }^{19}$.FU RTADO, Júnia Ferreira. “O Labirinto da Fortuna: ou os Revezes na Trajetória de um Contratador de Diamantes. In H istória: Fronteiras. São Paulo: XX Simpósio N acional da AN PUH, 1999, pp. 309-320; "Autos de Sequestros e perguntas sobre o ouro e brilhantes pertencentes a indivíduos do Rio de Janeiro", ANTT, Intendência Geral da Polícia, maço 601; Requerimento de Francisco Xavier Telles para o rei, analisado em 15 fevereiro, 1777, AHU, Rio de Janeiro, p.a., caixa 111, doc. 25; Alvará 29 agosto, 1720, AHU, Rio de Janeiro, p.a., caixa 13. doc.28. 
${ }^{20}$ M O NTEIRO, N uno Gonçalo. “O Endividamento Aristocrático (1750-1832) : Alguns Aspectos", A nálise Social, pp. 116-117, 1992, pp. 263-283. N o que se refere a Lavradio, M onteiro argumenta que os poucos nobres que fizeram fortuna no Brasil eram exceções à regra, e que esses nobres encaravam seus serviços no exterior como um sacrifício: 0 Crespúsculo dos Grandes. A Casa e o Patrimônio da Aristocracia em Portugal (1750-1832). Lisboa: Imprensa N acional Casa da M oeda, [1996], pp. 536-540; M ONTEIRO, Nuno. “Poder Senhorial, Estatuto N obiliárquico e Aristocracia". In HESPANHA, H istória de Portugal, vol. 4, p. 336.

${ }^{21}$ ROM EIRO. "Confissões de um Falsário”, p. 330; GONÇALVES, Adelto. Gonzaga, um Poeta do Iluminismo. Rio de Janeiro: Nova Fronteira, 1999, pp. 205-206.

${ }^{22}$ (...) "unlawful dealing against law or proclamation", "anything prohibited to be imported or exported", "but the actual form in contra- appears to have come directly from the contraband traffic with the Spanish possessions c. 1600", "bold and true son of M assachussetts", "idlers and gypsies". MURRAY, James A.H. et al (orgs.), The O xford English Dictionary. being a Corrected Reissue with an Introduction, Supplement, and Biography of a N ew English Dictionary on Historical Principles Founded $\mathrm{M}$ ainly on the $\mathrm{M}$ aterials Collected by the Philological Soci ety. Oxford: Clarendon Press, 1933, 3, pp. 833-834.

${ }^{23}$ D espacho do conde de Resende para dom Rodrigo de Souza Coutinho, secretário de Estado, 12 dezembro, 1798, AHU, Rio deJaneiro, p.a., caixa 175, doc. 87.

${ }^{24}$ Despacho de Luís de V asconcellos e Souza para M artinho de M ello e Castro, secretário do Estado, 2 outubro, 1784, BN RJ, ms. 4,4,6, fl. 216v.

$414{ }^{25}$ Despacho do marquês de Lavradio para M artinho de M ello e Castro, 11 setembro, 1770, AHU, Rio de Janeiro, p.a. caixa 97, doc. 57.

${ }^{26}$ W ALPOLE, "Observations on the answer", 26 maio, 1769, British Library, Additional M anuscripts 9252, fl. 57v-58v; Alvará 14 novembro, 1757, Collecção das Leis, Decretos e Alvarás. Lisboa: Officina de António Rodrigues Galhardo, 1797, vol. 1.

${ }^{27}$ ANTONIL, Andréjoão. Cultura e O pulência do Brasil por suas Drogas e M inas. Texte del'édition de 1711, traduction française et commentaire critique. MANSUY, Andreé. (org.). Paris: Institute des H autes Études del'Amérique Latine, 1968, pp. 394-416.

${ }^{28}$ ANTONIL, André João. op. cit., p. 338; Despacho de Gomes Freire de Andrade para o rei, 24 junho, 1754, AHU, Rio de Janeiro, papéis avulsos catalogados, Castro e Almeida, 16.214; M emorando de Pina M anique, superintendente de contrabando em Lisboa, 6 outubro, 1784, AHU, Rio de Janeiro, p.a., caixa 134, doc. 32A, Despacho de Donald Campbell, almirante da frota do Brasil e da Guarda Costeira para dom Rodrigo de Souza Coutinho, 7 abril, 1801, AHU, Rio de Janeiro, p.a., caixa 191, doc. 84; BISMUT, Roger. (org.). Arte de Furtar. Lisboa: Imprensa N acional Casa da M oeda 1991, pp. 13-37.

${ }^{29}$ COUTO, Diogo do. 0 Soldado Prático. LAPA, M. Rodrigues. (org.), 3ạ ed., Lisboa: Livraria Sá da Costa, 1980; Arte de Furtar, capítulos 2 e 16; Arte de Furtar, pp. 371-377.

30. GONZAGA, Tomas Antônio. Cartas Chilenas. FURTADO, Joaci Pereira. (org.). São Paulo: Companhia de Letras, 1995; M ATOS, Gregório de. O bra Poética. AM ADO, James \& ARAÚJO, Emanuel. (orgs.), 2 vols., 3ạ ed.; Rio de Janeiro: Editora Record, 1992.

\section{Artigo recebido em 01/2001. Aprovado em 10/2001.}

Revista Brasileira de História, vol. 21, nำ 42 